\title{
REVISIT CHALLENGES FOR TEACHING COMPUTER LITERACY: A CASE OF USING AN ONLINE SIMULATION TOOL
}

\author{
Thomas Ngo-Ye, Alabama State University, Thomas.NgoYe@gmail.com \\ Jae Choi, Pittsburg State University, jchoi@pittstate.edu
}

\begin{abstract}
This paper presents an exploratory case study of using SIMnet, an online simulation tool for teaching Microsoft Office 2013. It attempts to identify the challenges students are facing through our direct classroom observation. A critical analysis was conducted with the conceptual lens of empathetic thinking and disruptive information technology (IT) innovation. This study will contribute to a general understanding of the challenges faced by students in computer literacy education. Moreover, it also provides a pedagogical introduction of SIMnet to instructors interested in teaching Office 2013 utilizing a simulation tool. Our own SIMnet configuration details and tips are provided as well so that instructors can start their SIMnet journey armed with the knowledge of what to expect.
\end{abstract}

Keywords: Computer Literacy Challenge, Empathetic Thinking, Disruptive IT Innovation, Microsoft Office 2013

\section{INTRODUCTION}

One of the critical goals of university general education is to develop students' computer literacy. Elementary computing skills in basic applications such as Microsoft Office 2013 are anticipated by most potential employers [7]. This study presents an explorative observational case study of applying SIMnet for Office 2013 education. During the study, we noted that some students lack or have very low-level basic computing skills although student subjects in this study are from the generation grown up with rich information technology and surrounded by Internet, online social media, and smart phones. To understand why the computer literacy skills are huge challenges to those students, we adopt the perspectives of empathetic thinking [12] and the disruptive information technology (IT) innovation theory [13]. While pedagogical simulation tools like SIMnet is very useful for teaching and learning Office 2013, we discover that one-on-one hands-on tutoring is still a very effective way of teaching computer literacy.

This study contributes to the collective understanding of the challenges in computer literacy education, taking the conceptual lens of empathetic thinking and disruptive IT innovation. A major advantage of online simulation environment for teaching Office 2013 was identified in the process- alleviating the burden of acquiring Windows Operating System (OS) skills. Dividing computer literacy skills into OS-level skills and application-level skills is another effective way to investigate computer literacy challenges. Moreover, this study also has practical implications. For IS educators unfamiliar with SIMnet, this paper serves as an introductory tutorial, explaining relevant SIMnet components from the perspective of instructors. New adopters of SIMnet can start with our suggested configurations. Furthermore, the documented challenges can help instructors better prepared for their SIMnet journey.

\section{BACKGROUND AND LITERATURE REVIEW}

In current job market students need to be proficient in computer skills and these computer skills include word processing, presentation, and spreadsheet applications [6]. Employers have increased their expectations of college graduates' computer literacy, with word processing and spreadsheet skills ranked as most needed from business graduates [9]. Organizations increasingly administer their own computer literacy tests and instructors need to pay more attention to computer literacy assessments [4]. An empirical study involving more than 500 students shows that students who did better on online assessments with SIMnet also did better on traditional in-class examinations [1]. 
One study discovers that although college students are computer literate in the often used and more familiar email, Internet, and word processing, they are not literate in spreadsheet application and general computer technology [2]. Another study shows that despite students seem to be comfortable with many information technologies, it is wrong to assume they possess the computer skills demanded by the employers and they can learn these skills on their own [10]. While some business school faculties suggest to remove computer literacy course on the ground that students already obtained computer skills from high school and work experience, many studies indicate that many students still need and benefit from the computer literacy course [8]. A recent empirical study finds that the unexpected problem for computer literacy course is students' lack of basic computer skills to start with [16].

An empirical study finds that there are significant gaps between students' actual computer skills and their selfperceived skills [3]. Another empirical study finds that college students' self-perceived computer skills differ from their actual abilities measured by their actual scores on a computer skills assessment conducted through SAM from Course Technology, a simulated Microsoft Office environment [6]. Online pre-tests results reveal that students entering the introductory computer applications course are not "computer literate", although post-tests scores are significantly higher [11]. McGraw-Hill's SimNet was chosen to administer those online pre- and post-tests, which returned test results immediately to students and instructors [11].

SIMnet from McGraw-Hill is one of many online assessment and training tools for computer applications (e.g. Microsoft Office) created by textbook publishers for the university market [4,6]. SIMnet, a simulated Microsoft Office training and assessment computer software package, was used for hands-on assessment of students' actual skills to complete specific application tasks [3]. SIMnet is primarily focused on the sets of skills evaluated by the Microsoft Office Specialist exams. SIMnet emulates the Microsoft Office User Specialist (MOUS) certification exam environment and makes students to complete tasks within that environment [11]. SIMnet also provides online training segments for students [4]. SIMnet exam questions ask students to perform actual tasks in its simulated application environment [4].

SIMnet from McGraw-Hill Technology Education was chosen as the software tool in a laptop inclusion program, aiming to integrate technical skills with information systems concepts in an introductory MIS course [5]. As an assessment and tutorial tool, SIMnet is an online virtual platform simulating a Microsoft Office application learning environment [5]. SIMnet's tutorial segment used to have three approaches - "Teach Me" with text and pictorial explanation of functional tasks, "Show Me" with video animation and audio narration, and "Let Me Try" with elements students can work on [5].

In another empirical study to examine whether computer-simulated learning software - SIMnet -is a useful way of delivering course content, the authors find that students' scores on Microsoft Word, PowerPoint, and Excel have dramatically increased from pre-test to post-test [18]. Based on student survey and interviews with teaching assistants, the authors conclude that SIMnet as a computer-simulated learning software is a worthwhile investment for the introductory computer course [18]. With the potential of serving as a computer-based resource for long-term future reference for students, a computer-based training supplement such as SIMnet is recommended to be added as a requirement of the computer literacy course [9].

The simulation-based skills assessment tools, such as SIMnet, are attractive to instructors and students, because they provide an environment for interactive performance evaluation and give users immediate test results [19]. In the real-live performance-based assessment, students perform tasks in real computer application such as Microsoft Office and instructors manually check students' finished documents. Manually grading students' documents is labor-intensive and time-consuming [19].

The current study aims to explore the challenges involved in computer literacy education. Specifically, it examines if and when simulation approach is effective in computer literacy education. As shown in the above literature review, most studies focus on using SIMnet only as a computer skills assessment tool. There is very little discussion about adopting online simulation tool - SIMnet - to teach Microsoft Office. When we started implementing SIMnet for teaching Office 2013, it was surprising to find that very little resources are available for instructors. The materials provided by the publisher are not designed to help instructors who use SIMnet in a classroom setting. It takes a great deal of time and effort to figure out the implication of different SIMnet components and how to use 
them in the coursework. Noticing that other IS instructors face the similar challenges, we elected to document and share our experiences of using SIMnet in the current study.

\section{METHODOLOGY}

An exploratory empirical observational case study was conducted. It is primarily descriptive in nature. First, the implication and conceptual definition of SIMnet framework are discussed. Next, the procedures and strategies of SIMnet implementation to teach Office 2013 are described in detail. The SIMnet components and configurations employed in our class are discussed as well. We critically analyze the advantages of using SIMnet for teaching Office 2013. Finally, the first-hand classroom observations of challenges faced by students are fully documented. This study is based on a careful and systematic classroom observation during the Fundamentals of Computer Applications class in spring 2015. The adopted textbook is "Microsoft Office 2013: In Practice" [17], which includes complementary SIMnet for Office 2013 (http://successinhighered.com/cit/simnet/). The class lasted for 17 weeks with one class meeting in each week. There were a total of 14 students in the class and one student dropped the class before the middle of the semester. After each class meeting, classroom observation items were recorded. We kept this practice for the whole semester. In the following section, we report on the issues students found challenging and the methodology we applied to solve the problem. The direct classroom experiences described by this case study offer rich information on the phenomenon examined $[14,15]$. We recognize the possible bias and the concern of the generalizability of this study. Nevertheless, the main objective of this exploratory study is to gain the initial understanding of the problem. The future studies will benefit from the insight brought out by this study.

\section{EXPLORATORY CASE STUDY OF USING SIMNET FOR TEACHING MICROSOFT OFFICE 2013}

\section{Our Own Take on SIMnet}

In order to improve students' learning experience in computer literacy education, a variety of online simulation tools were evaluated and SIMnet, a virtual Microsoft Office environment, was adopted. It enables students to work on a web browser which simulates Office 2013 environment, and is marketed as McGraw-Hill's leading training and testing tool for Office 2013. SIMnet is designed to develop students' skills and confidence with a variety of realistic simulations, and help students prepared for business work environment.

In the beginning of each class meeting, covered chapters and assignments are announced to students. Then students are asked to work on the tasks in their own pace. They are encouraged to ask questions whenever they encounter difficulties. Instructor walks around the classroom every few minutes to monitor students' progress and offer help.

Teaching Office 2013 with SIMnet significantly differs from the traditional approach where students work directly on genuine Office 2013 applications. Since students need to maneuver at OS level with the traditional approach, lacking the basic skills of Windows file and folder operation becomes a major roadblock for learning the application level skills. With a simulation environment like SIMnet, the majority of course contents including assignments are delivered over Internet which does not require OS skills. Thus, simulation approach greatly reduces the burden of working at OS level and the corresponding frustration.

\section{Three Types of SIMnet-based Assignments}

Three types of SIMnet-based assignments: "simbook", "exam", and "project" were adopted in the class.

\section{SIMbook}

Students can read textbook chapter contents on a web browser. In addition to the traditional passive reading function, "simbook" offers three active activities. The first one is "show me". When students click the blue "show me" button, a new web browser window pops up running a very short video tutorial for a specific task. The video demonstrates the concrete actions in Office 2013 with audio explanation. The video is normally less than one minute long. Students can replay the video many times. Each chapter of the textbook contains about a dozen such video tutorials. We recommend students to read the textbook chapter online and watch each and every video tutorial to 
learn the content of Office 2013. SIMnet video tutorials are suggested as the first step in learning Office 2013. If students still have problems, instructors need to provide help in person.

The second type of activity in "simbook" is "guide me". When students click the orange "guide me" button, a separate web browser window pops up. On the top-left corner of the new window, it shows very detailed step-bystep guide, such as "Click Page Layout tab". After students perform an action, it gives instant feedback. If the student's action is correct, it asks students to click to move to the next step. If the student's action is wrong, it tells student the right steps to follow to get it right. Students can practice a "guide me" activity as many times as they want.

The third type of activity in "SIMbook" is "let me try". When students click the green "let me try" button, a new web browser window appears. On the top-left corner of the new window, it gives very brief instruction, such as "Open the Page Setup dialog box" or "Change the Top and Bottom margins to 0.75 ." It only states what need to be done, not how to do it. It is up to the students to perform several detailed steps to complete a relatively large task. The feedback mechanism is the same as that of "guide me". Comparing to "guide me", "let me try" is more challenging, because the task is at higher granularity level than that of "guide me" and less instruction is provided. However, right above the brief instruction of "let me try", there is a grey button "NEED A HINT?" When students have trouble with the "let me try", we suggest students to click this button to get instant help. It provides detailed procedures. For example, the hint for "Open the Page Setup dialog box and Change Top and Bottom Margin to .75" is "Click the Page Layout tab, and click the Margins button [Page Setup group]. Select Custom Margins from the drop-down list. Click the Top box, delete the existing margin, and type 0.75. Click the Bottom box, delete the existing margin, and type 0.75 ." Students can also practice a "let me try" activity as many times as they want. There is no time limitation of "guide me" or "let me try" activities. Thus, students can take their time and work with their own pace. We setup "simbook" assignments for each textbook chapter. We also require students to complete all "let me try" activities to get grade for "simbook" assignment. If students skip some "let me try" activities, certain corresponding points will be automatically deducted from their grade. In this way, we give students incentive to complete all "let me try" activities.

\section{SIMnet Exam}

The second type of SIMnet assignment is SIMnet "exam". It is hands-on exam delivered via SIMnet online simulation environment. It is not a traditional standard multiple choice question based exam. For example, a SIMnet exam question is "Save the document to the Documents folder in Neil Patella's OneDrive with the name brochure." SIMnet exam is similar to "let me try" in the way that students need to perform certain actions in the SIMnet simulated Microsoft Office 2013 environment. However, SIMnet exam differs from "let me try" by not providing any hint. The feedback mechanism of SIMnet exam is the same as that of "let me try". If students performed wrong actions for an exam question, SIMnet gives instant feedback of the correct sequence of actions, such as "Click the File tab. Click Save As. Click Neil Patella's OneDrive under Recent Folders. Double-click the Documents folder. Type brochure in the File name box and click the Save button."

From our previous class observation, we noticed that it took some students a bit longer time to accomplish simulation-based tasks and exams. One female student mentioned that she took a computer literacy class before for Microsoft Office 2007 using a different online simulation tool. However, somehow her previous teacher set up that online simulation environment in a way creating a lot of time pressure for students in that class. This student told us that she felt it was way too fast. She liked to work on her own pace. She said that she could learn more when she was not constantly worried about running out of time.

In SIMnet, there is no time length limit for completing "guide me" or "let me try" activities of "simbook" assignments. Students can take their time to work on these "simbook" assignments. For SIMnet exams, the default setting for completing an exam is 30 minutes. The number of questions for each chapter is different, ranging from 16 questions to 75 questions. To ease the time pressure for students taking SIMnet exams, we extend the time length limit to 60 minutes. Therefore, students have enough time to complete exams. So far, we have not witnessed any students who ran out of time for SIMnet exams. In addition to extending exam time length limit, we also allow students to have two attempts for each exam, instead of just one attempt by default. In this way, students have the opportunity to get it right the second time, just in case that they made a mistake by accident in the first attempt. 


\section{Advantages of SIMbook Assignment and SIMnet Exam}

A clear benefit of using "simbook" assignment and SIMnet exam is that they provide students with hands-on learning experience even if Microsoft Office 2013 is not installed on the computer. Students can practice Office 2013 skills as long as they have a PC, an Internet connection, and a web browser. It reduces students' financial burden of purchasing Office 2013 for their private computers.

Second, SIMnet's virtual Microsoft Office 2013 environment bypasses the Windows OS concept and the associated challenges of dealing with files and folders on local hard drive/flash drive. By circumventing the Windows file and folder operation, SIMnet enables students to concentrate directly on the Office 2013 application content, rather than being dragged down by Windows OS operations. This new approach of delivering learning contents through a web environment greatly simplifies the process and removes a lot of huddles. Students are all familiar with web browsers and online environment. Therefore, it dramatically reduces students' frustrations due to troubles with basic Windows OS operations.

Third, SIMnet offers immediate feedback to students, after they complete each small task. When students see that they did it correctly, it helps to build their confidence in working with Microsoft Office 2013. It also encourages students in learning. When students performed wrong action in SIMnet, they get detailed feedback of what the correct steps should be. So students can learn instantly from their mistakes. Providing critical and frequent feedback is regarded as the most critical factor for collaboration to succeed [12]. Timely feedback is important for learning and improving performance. Thus, for students learning Office 2013, immediate feedback is very valuable.

Finally, SIMnet facilitates students to work on their individual pace in the self-study mode. In the traditional teaching mode, instructors do big screen demonstration to the whole class. It requires every student to follow along to be on the same page. Often some students encounter problems and need the instructor's help. This will unavoidably slow down the whole class's progress, because other students have to wait until the instructor finishes helping those students to move on to the next learning task. As a self-learning tool, SIMnet allows students to work on their own. When students have questions, they can ask instructor for help in class.

\section{SIMnet Project}

The third type of SIMnet assignment is SIMnet "project". It is hands-on project. Project instructions, start-file, and potential resources, such as pictures and data files, can be retrieved from SIMnet website. After obtaining these files, students proceed to work in the real Microsoft Office 2013 environment. We configure SIMnet projects in the way that students are allowed only one attempt and then SIMnet displays visual feedback after the attempt. One benefit of SIMnet project is that students can see the report of how they are doing immediately. Students need to follow the following steps to complete a SIMnet project.

First, students need to get project files by downloading the required project files using the web links on the SIMnet website. After obtaining project instructions, start-file, and resource files, students can open the project instructions file to begin.

Second, students work on the project in the real Microsoft Office 2013 suite and save the project. Students can save their in-progress or completed project work by clicking "Upload \& Save" button and select the project file on student's computer. This action will replace any existing file that has been previously uploaded and saved for this project on SIMbnet website.

Third, when students are done with a project, they need to submit the project for grading. In order to submit a project for grading, students need to first upload \& save the completed project file to SIMnet website. The Submit Uploaded File wizard will let students grade their project file immediately by clicking "Yes, submit the file". Students can also use the Upload \& Save feature to save their project online, to retrieve later by clicking "No, I'm not ready".

Fourth, students need to submit their project for grading by SIMnet automatically. If students choose "No, I'm not ready" in step 3, now click the "Grade my project" button to submit their project for grading. 
After students' project has been graded, students can click "GRADES" weblink on the top of SIMnet website. After locating the project graded, students can look for the eye icon "view result" for results that are available. SIMnet gives detailed feedback on which step was wrong. SIMnet visually highlights the wrong part by putting a red marker next to it, such as "8.h", as well as providing a textual explanation. For example, it shows the step a student missed "8.h Right-click the Book Title style in the Style gallery and select Update Book Title to Match Selection. The Book Title style is updated." and the feedback is "Text in paragraph 4 does not have any style settings".

For SIMnet projects, we do not set any time limitation. Students can take their time to complete the SIMnet project assignments. Different from Simbook Assignment and SIMnet Exam, students cannot work in a web browser environment for SIMnet project assignments. Instead, students must work in the real Microsoft Office 2013 environment on a desktop/laptop PC. We recommend students to work on SIMnet projects in class meetings. There are two benefits for students doing SIMnet projects in class meetings. First, most students do not have Office 2013 installed at their home PCs and many students do not have financial resources to purchase Office 2013. Therefore, using Office 2013 installed in the computer classroom alleviates the access issue. Second, we expect that students will encounter more difficulties in SIMnet projects than Simbook Assignments and SIMnet Exams. Thus, having students work on SIMnet project in class meetings makes it easier for students obtaining immediate face to face help. We will highlight this benefit in the section of classroom observations.

Once setting up SIMbook assignments, SIMnet exams, and SIMnet projects, instructors can concentrate on helping students to solve problems. SIMnet online software grades all the assignments, exams, and projects. Therefore, adopting SIMnet for teaching Office 2013 not only ensures consistent, fair, and objective grading, but also greatly frees up instructors' time for other value-added activities. For SIMnet projects, students still need to download files from SIMnet website to a local storage, such as a flash drive or a local hard drive on a PC. While SIMnet website automatically grades submitted project, SIMnet only reduces the degree of reliance on local storage. Students still need traditional Windows file and folder operation skills to finish SIMnet projects.

\section{Classroom Observations}

In the first two weeks of the class, we were occupied with introducing students the student learning outcomes, policies and rules of the class, how to register and use SIMnet for homework assignments. From the third week, we started encountering students' requests for help, because they began real work. Students worked on their own pace and therefore we were asked about the same issue in different weeks by different students. Overall, we found that even online simulation tool helps a lot, some students still need in person help.

\section{Third Week of the Class}

Student A asked us why her SIMnet Word Chapter 1 project result did not look like the one in her textbook. She stressed that she deleted space between paragraphs as required by the instruction and therefore her result should be right. We found that she had several versions of the project. It turned out that she missed several steps, which she did not recognize. We walked her through those missing steps.

\section{Fourth Week of the Class}

Student B asked us which textbook to purchase before putting his credit card information online. We started the class three weeks ago and it was already the fourth week into the spring semester. We also found that some students did not have flash drive for this class or their flash drive did not work. Student C asked us why her SIMnet Word Chapter 1 project result did not look like the one in her textbook just like the other student asked last week. We found that she did not delete the lines as specified in the instruction. We told her that we noticed that she missed one step. She asked us why even if fixing this step, her result still looked different than the book result. Our suggestion was that she had to double check again all the steps. Student D asked us why an error happened in a SIMbook Assignment. She was supposed to type "-". The instruction told her to type - (hyphen). She did type in "hyphen" and ended up with error. We explained to her that she just needed to type "-" and it worked. Student A did not know how to use Ctrl key to select several rows. We physically showed her how to do so. 


\section{Sixth Week of the Class}

Student A asked us for help when she worked on SIMnet Word Chapter 4 project. The task was to insert a picture into a Word document. Her issue was that she inserted a shortcut of the resource zip file into the Word document. Somehow she created a shortcut to the resource zip file. She inserted the shortcut instead of the unzipped photo file. Hence, it did not work. She did not read the instruction of Downloading Start Files and Extracting Resources.zip Folders. We guided her on how to download the Resources.zip from SIMnet website to her desktop. We unzipped it and helped her locate the picture file. Finally, she inserted the picture successfully into the Word document. Student E misread the instruction. The instruction asked students to select a column in a table in a Word document. However, he selected a row and it did not work. We reminded him the reason and he fixed the problem.

\section{1th Week of the Class}

Two students had issue with creating absolute referencing in Excel. They did not know how to do it. We manually showed them to put "\$” sign in front of cell address, such as $\$ A \$ 5$.

\section{2th Week of the Class}

Student B asked us for help. Last week he worked on a SIMnet Word Chapter 4 project and he did not finish it in class. His project work in Word document was stored on the desktop of a PC in our computer classroom. He did not bring a flash drive. When he left the classroom last week, his project work was lost, because he did not know a way to get his Word document out of the classroom desktop PC. The classroom PCs are configured in a way that all students' files will be gone after they logoff. Therefore, he had to redo the project from the beginning. We suggested him to bring his flash drive to save his project file or email the Word project document to his own email as attachment. We showed him how to locate the Word document on his desktop. He asked us how to email and attach his Word document. We showed him how to do so step-by-step. Student C had issue with SIMnet Access 2013 project. In her Access 2013 database table, she had "Rental ID" as field name. However, in the Excel 2013 data she imported, it had "RentalID" as column header. They did not match. We reminded her that the Access database table field name and Excel column header must match to make the import process work. We helped her fix the problem by renaming the field as "RentalID". Then we found that she did not have field "FourhourRental?" in her Access database table, while the Excel data file had it. So they did not match again. We helped her fixed this and then the import process worked. We helped student D select cell E5 and type "=Today()" to display current date each time Excel is opened.

\section{3th Week of the Class}

We found that Access Chapter 2 SIMbook assignment did not work in Microsoft Internet Explorer. When clicking button "let me try", nothing happened. However, after switching to Firefox, it worked. We announced this workaround to the whole class. Student A had problem with SIMnet Access Chapter 1 project. SIMnet complained that the signature of her submitted file did not match. We discovered that she changed file name and therefore SIMnet did not recognize it as her work. We suggested her to re-work from the SIMnet start file and not change the file name of the Access database.

\section{4th Week of the Class}

We were approached for the same problems of importing Excel data to Access Database's existing empty table. Student A had her Access database table opening while trying to import Excel data. It popped up an error box explaining the issue. We helped her to close Access database table and the import process proceeded beyond this step. Next, she encountered another issue. The column name "FourHourRental?" was in the Excel data file. However, when the student created the corresponding Access database table field name, she mistakenly spelled it as "FourHourRental". Due to the mismatch between Excel column name and Access database table field name, the import process failed. We helped her copy the Excel column name into Access database table field name. Then the import process proceeded beyond this step. Next, she encountered another problem. She had the Excel data file to be imported open while trying to import data into Access database table. This leaded to an error. We helped her close the Excel file. Then the import process finally worked. Access Chapter 2 SIMbook assignment did not work in 
Internet Explorer. We mentioned this in class meetings several times to warn students about this issue and suggested students to try Firefox instead of Internet Explorer. But student D did not know this and asked us to help her on this matter in class. Last week (13th week) student B saved his Word project in progress in email attachment sent to himself. We helped him to download it to his desktop to resume the Word project.

\section{5th Week of the Class}

Student E had issue with importing CSV file data into an Excel file. The problem was that he did not unzip the downloaded zip file. After we unzipped the downloaded zip file, we helped him to navigate to the extracted folder and imported CSV data into the Excel file.

\section{6th Week of the Class}

Student E encountered an error when doing "Use Goal Seek" in SIMnet Excel Chapter 4 project. The reason was that he somehow worked on a wrong file - the downloaded file ClemensonExpenseData-04.csv. He imported the CSV data to his Excel file. He should continue working in his Excel file. But he worked on the CSV file instead and it set him a few rows off. Therefore, there were no formula in the target cell to do goal seeking. We guided him to restart the work from the right Excel file.

\section{7th Week of the Class (Last Week of the Class)}

When doing a SIMnet Access Chapter project, student B did not know how to save a table in Access 2013 database. We showed him to click save button and typed "SDRentals" as the new table name. Student B had trouble to import Excel data into SDRentals table in his Access database. We showed him how to download resource zip file from SIMnet website to desktop. Then we unzipped it and located the Excel data file for him. We discovered that when importing Excel data, the structure/configuration/data type of Access table SDRentals did not match that of Excel data file. We explained to him that he did something wrong when setting up his Access database table SDRental. We deleted his table SDRentals and then imported Excel data into a brand new table, rather than appending data to an existing table. This workaround did work. Then we suggested him to redo relationship between two tables and setup date validation rule for field - RentalDate - as specified in the instruction. When student B was done with the SIMnet Access 2013 database project, he did not know where he stored his Access file. We located his Access file on his Desktop and helped him to upload it to SIMnet website for grading.

\section{DISCUSSION}

The above empirical evidences obtained from our direct classroom observations clearly demonstrate that some students do struggle with basic computer literacy skills. While SIMnet online simulation environment and textbook provide immense value to students, some students still stand to benefit from face-to-face class instruction focusing on trouble-shooting problems encountered by students. Some students do need assistance from teachers to overcome various issues. It seems that this one-on-one personal tutoring style teaching approach is most desirable to students.

IS educators may assume everyone has the basic computer literacy, which is taken for granted for $21^{\text {st }}$ century knowledge workers. This is clearly not the case based on our current study. Why are our expectations different from the classroom reality observed? Why do students struggle with basic computer literacy class? We attempt to address these questions from the perspectives of empathetic thinking and disruptive information technology (IT) innovation.

\section{Empathetic Thinking}

People tend to assume that every college students are computer literate and know basic computer skills. This assumption is questionable especially for students admitted into an open access institution. The fundamental reason behind such false assumption is ego thinking - thinking that other people should know and behave just like ourselves [12]. People often think others behave the same as them or possess the same skills. We, IS educators, think technology is easy to learn and use. Thus, if some computer tasks are easy for us, it must be easy for students. People tend to over-generalize it to others. Therefore, it is hard to be neutral and hold an objective view to understand people other than our group. Many people fail to recognize that there are huge differences among people 
in terms of computer background and past experiences. Our classroom observations clearly demonstrated that the assumption is not true. In the observed class many students struggled with elementary computer operations.

\section{Disruptive Information Technology (IT) Innovation}

Many of the observed issues are related to traditional thick-client Windows-based basic skills. Many students are not familiar with file manipulation in the thick-client Windows based environment. They can use Facebook/Tweeter, but not able to conduct Windows-based thick-client operations such as using Ctrl key to select multiple cells, closing files, locating and organizing files, folders, sub-folders, zipping and unzipping files. It was also observed that many students in our class just double-clicked a file on SIMnet website and opened it, rather than downloading and saving it to a local hard disk drive or a flash drive. They had little understanding of file, folder, save, and Windows file operations. To understand why students struggle with these seemingly simple Windows-based basic operations, we approach it with the theoretical lens of disruptive IT innovation.

In the past decades, computer technology progressed in a disruptive manner. Moreover, one generation of computer skills does not necessarily transfer to the next generation of disruptive technology. Windows-based applications and file operations are dramatically different from previous generation of computer technology. Internet-based webapplications are another major leap. It is so different from Windows-based applications. Hence, in the Internet era, the web-based systems are again disruptive [13]. Because of this very disruptive nature of computer innovations, having simple web skills, e.g. reading online news and checking web-based email, does not translate back to knowledge of manipulating files and folders in a Windows environment.

Therefore, the take home message is that for students without basic computer skills - defined as Windows file manipulation, zip and unzip - even a seemingly simple and easy task is a mounting challenge. To help Windows novices overcome the basic hurdles, instructors need to hold hands and tutor closely, although it may be very time consuming.

\section{CONCLUSIONS}

IS instructors and university administrators may assume that all students master basic computer skills. This study clearly demonstrates that this is not the case. Our first-hand classroom observations reveal the struggles that some students have in our computer literacy class. Some students have trouble with basic computer skills, although they have used computer, Internet, and smart phone for years. Because of the disruptive nature of IT innovation, these students' experiences with simple web applications and mobile applications do not transfer back to the traditional thick-client Windows-based OS basic skills such as zipping and unzipping files. From our classroom experiences, we suggest that computer literacy instructors should 1) adopt online simulation tool, such as SIMnet, to facilitate students' learning; 2) spend more class meeting time on one-on-one hands-on tutoring to assist students, who need individual attention.

This research has a few possible implications. The findings of this study may help some students relieve stress from computer literacy class, because our work demonstrates that they are not the only one dealing with the challenges of computer literacy class. Students may also find that it is natural and normal to struggle with a different generation of technology. By sharing our SIMnet experiences and observations, other IS instructors, who are considering adopting this new tool, can be better informed of how SIMnet works and what kinds of challenges they can expect. This study also contributes to the literature by applying the concepts of empathetic thinking and disruptive IT innovation to understand the challenges of teaching computer literacy. Moreover, our research also highlights the important distinction between OS-level skills and application-level skills. This way of classification offers a useful angle to examine computer literacy challenges.

We admit that this exploratory case study has its own shortcomings. We arrive at the conclusion based only on our observations in one class. To improve the validity of this research, we need to enlarge the sample size and adopt more structured and systematic methods. Nevertheless, this research, as an initial attempt, does provide a rock-solid ground for future study. 


\section{REFERENCES}

1. Amoroso, D. L. (2005, August 1). Use of online assessment tools to enhance student performance in large classes. Information Systems Education Journal, 3(4), 1-10. Retrieved from http://isedj.org/3/4/ISEDJ.3(4).Amoroso.pdf

2. Creighton, W., Kilcoyne, M., Tarver, R., \& Wright, S. (2006). Computer literacy levels of students enrolling in a post-secondary computer applications/ information technology course. Information Technology, Learning, and Performance Journal, 24(1), 15-23.

3. Easton, A. C., \& Easton, G. (2003). Closing the gap: Proficiency vs. perception. International Business and Economics Research Journal, 2(10), 11-14. Retrieved from http://www.cluteinstitute.com/ojs/index.php/IBER/article/view/3847

4. Easton, A. C., Easton, G., \& Addo, T. (2006, February). But I am computer literate: I passed the test. Journal of College Teaching \& Learning, 3(2), 39-44.

5. Fitzgerald, S. M., \& Robak, N. J. (2004). Successful fusion of information systems concepts with complementary technical skill. Journal of Business \& Economics Research, 2(11), 41-48. Retrieved from http://www.cluteinstitute.com/ojs/index.php/JBER/article/view/2938

6. Grant, D. M., Malloy, A. D., \& Murphy, M. C. (2009). A comparison of student perceptions of their computer skills to their actual abilities. (J. Whatley, Ed.) Journal of Information Technology Education, 8(1), 141-160.

7. He, J., \& Guo, Y. M. (2011). Should I take MISXXX? Implications from interviews with business recruiters. Proceedings of the Seventeenth Conference on Information Systems (pp. 1-9). Detroit, Michigan: Association for Information Systems.

8. Hungerford, B. C., Baxter, J. T., LeMay, S., \& Helms, M. M. (2012, August). Strategies for ensuring computer literacy among undergraduate business students: A marketing survey of AACSB-accredited schools. Information Systems Education Journal, 10(4), 49-73. Retrieved from http://isedj.org/201210/N4/ISEDJv10n4p49.pdf

9. Johnson, D. W., Bartholomew, K. W., \& Miller, D. (2006). Improving computer literacy of business management majors: A case study. (M. Hart, Ed.) Journal of Information Technology Education, 5(1), 77-94.

10. Jones, M. C., Windsor, J. C., \& Visinescu, L. (2011). Information technology literacy revisited: An exploratory assessment. ACM Inroads, 2(2), 59-66.

11. Kline, D., \& Strickland, T. (2004). Skill level assessment and multi-section standardization for an introductory microcomputer applications course. Issues in Information Systems, V(2), 572-578. Retrieved from http://iacis.org/iis/2004/KlineStrickland.pdf

12. Kroenke, D. (2014). Experiencing MIS (4th ed.). Upper Saddle River, New Jersey, U.S.A.: Prentice Hall.

13. Lyytinen, K., \& Rose, G. M. (2003). The disruptive nature of information technology innovations: The case of internet computing in systems development organizations. MIS Quarterly, 27(4), 557-595.

14. Myers, M. D. (1997, June). Qualitative research in Information Systems. MIS Quarterly, 21(2), 241-242.

15. Myers, M. D. (2012, November 5). Qualitative research in Information Systems. Retrieved January 4, 2013, from MISQ Discovery, updated version: http://www.qual.auckland.ac.nz/

16. Ngo-Ye, T. (2014). Computer literacy challenges for adult returning students, lost in a different generation of computer? Proceedings of the Ninth Midwest Association for Information Systems Conference (MWAIS 2014) (pp. 1-6). Ames, Iowa: Association for Information Systems. Retrieved from http://aisel.aisnet.org/mwais2014/14

17. Nordell, R., Wood, K., Easton, A., \& Graves, P. (2014). Microsoft Office 2013: In Practice. New York: McGraw-Hill/Irwin.

18. Ogawa, M. B., \& Nickles, D. (2006). Evaluation of SimNet simulation software in large-enrollment courses. TCC 2006 Proceedings, (pp. 125-130). Retrieved from http://tcc.kcc.hawaii.edu/previous/TCC\%202006/ogawa_nickles.pdf

19. Tuparova, D., \& Tuparov, G. (2010). Automated real-live performance-based assessment of ICT skills. Procedia-Social and Behavioral Sciences, 2(2), 4747-4751. doi:10.1016/j.sbspro.2010.03.762 